\title{
Correction: Prophylactic human papillomavirus vaccination to prevent recurrence of cervical intraepithelial neoplasia: a meta-analysis
}

Bartels HC, Postle J, Rogers AC, et al. Prophylactic human papillomavirus vaccination to prevent recurrence of cervical intraepithelial neoplasia: a meta-analysis. Int J Gynecol CancerPublished Online First: 09 April 2020. doi: 10.1136/ijgc-2020-001197

Since the online publication of this article, the authors have noticed that the total number of patients was incorrectly stated as 3562 . The correct number is 2912 . This has led to changes in the abstract and results section, Table 1, figures and the supplementary appendix. Please see bold for changes that have been implemented:

1. The Results paragraph of the abstract now reads ' $A$ total of 5744 citations were reviewed; 5 studies comprizing 2912 patients were selected for the analysis. There were 1338 patients in the vaccinated group and $\mathbf{1 5 7 4}$ in the placebo or unvaccinated group. The incidence of histologically confirmed cervical intraepithelial neoplasia 2+was reduced in the vaccinated compared with the unvaccinated group ( $\mathrm{OR} \mathbf{0 . 3 4}, \mathbf{9 5 \%} \mathrm{CI} \mathbf{0 . 2 1}$ to $\mathbf{0 . 5 4}, \mathrm{p}=<\mathbf{0 . 0 0 0 0 1})$. The number needed to treat to prevent one recurrence was 27 . Both pre-treatment vaccination $(0 \mathrm{R} 0.40,95 \% \mathrm{Cl} 0.21$ to $0.78, \mathrm{p}=0.007$, number needed to treat -37 ) and adjuvant vaccination (OR $0.28,95 \% \mathrm{Cl} 0.14$ to $0.56, \mathrm{p}=0.0003$, number needed to treat $\mathbf{- 3 0}$ ) reduced recurrence rates.'

2. The highlights section has been updated to:

- Prophylactic or adjuvant HPV vaccination reduces the risk of recurrent CIN2+.

- The overall recurrence rate was $4 \%$, of which $1.7 \%$ occurred in the vaccination group and $\mathbf{4 . 7 \%}$ in the unvaccinated and placebo group.

- Ideal timing of HPV vaccination uncertain.

3. In Table 1, the fourth column titled Study Period now reads Study Inclusion Period. The data in columns Total N, Vaccination and Placebo/no vaccination have also been updated. Please see updated Table 1.

4. The Results section now reads 'A comprehensive search of databases resulted in a total of 5744 manuscripts, of which 1450 remained for review after removal of duplicate manuscripts (Figure 2). Following review of titles and abstracts, 47 full text papers were reviewed. Five studies were eventually included after meeting the study inclusion criteria $13,19,20,21,22$. In total, the studies comprised 2912 patients, with study sizes ranging from 311 to 1066 patients. The studies selected for meta-analysis included three post-hoc analyzes each of which were nested within a larger RCT, one prospective case-control trial and one retrospective case-control study (Table 1).

All manuscripts were published between 2012 and 2018, with patients included from 2001 to 2017. Of the 2912 patients, 1338 (45.9\%) were vaccinated and 1574 (54.1\%) received no vaccination, placebo or hepatitis A vaccine. Studies were included which defined recurrence of disease as

\begin{tabular}{|c|c|c|c|c|c|c|c|c|c|c|}
\hline \multirow[t]{2}{*}{ Author } & \multirow[t]{2}{*}{ Year } & \multirow[t]{2}{*}{ Country } & \multirow[t]{2}{*}{$\begin{array}{l}\text { Study } \\
\text { inclusion } \\
\text { period }\end{array}$} & \multirow[t]{2}{*}{ Study type } & \multirow[t]{2}{*}{ Total N } & \multirow[t]{2}{*}{ Vaccination } & \multirow[t]{2}{*}{$\begin{array}{l}\text { Placebo/ No } \\
\text { vaccination }\end{array}$} & \multicolumn{2}{|c|}{$\begin{array}{l}\text { Age range at time of } \\
\text { surgical treatment (years) }\end{array}$} & \multirow[t]{2}{*}{$\begin{array}{l}\text { Jadad } \\
\text { Score }\end{array}$} \\
\hline & & & & & & & & Vaccinated & Unvaccinated & \\
\hline \multirow[t]{2}{*}{$\begin{array}{l}\text { Hildesheim } \\
\text { (22) }\end{array}$} & 2016 & USA & 2004-2005 & $\begin{array}{l}\text { Post-hoc analysis } \\
\text { nested in larger RCT }\end{array}$ & 311 & 142 & 169 & $18-25$ & $18-25$ & 3 \\
\hline & & & & & & & & & & $\begin{array}{l}\text { Minors } \\
\text { Score }\end{array}$ \\
\hline $\begin{array}{l}\text { Ghelardi } \\
\text { (19) }\end{array}$ & 2018 & Italy & 2013-2017 & $\begin{array}{l}\text { Prospective case- } \\
\text { control trial }\end{array}$ & 344 & 172 & 172 & $18-45$ & $18-45$ & 21 \\
\hline $\begin{array}{l}\text { Garland } \\
\text { (20) }\end{array}$ & 2016 & Australia & 2004-2006 & $\begin{array}{l}\text { Post-hoc analysis } \\
\text { nested in larger RCT }\end{array}$ & 454 & 190 & 264 & $15-25$ & $15-25$ & 19 \\
\hline Kang (21) & 2013 & Korea & 2007-2010 & $\begin{array}{l}\text { Retrospective case- } \\
\text { control study }\end{array}$ & 737 & 360 & 377 & $21-45$ & $20-45$ & 24 \\
\hline Joura (13) & 2012 & Austria & 2001-2003 & $\begin{array}{l}\text { Post-hoc analysis } \\
\text { nested in larger RCT }\end{array}$ & 1066 & 474 & 592 & $15-26$ & $15-25$ & 24 \\
\hline
\end{tabular}


histological diagnosis of cervical intraepithelial neoplasia 2+. However, recurrence was assessed at various timepoints among the included studies with Ghelardi et al ${ }^{19}$ at 12 month followup, Garland et $\mathrm{al}^{20}$ and Joura et $\mathrm{el}^{13}$ at 60 days or more following treatment, Kang et al ${ }^{21}$ at 6 months, and Hildesheim et $\mathrm{al}^{22}$ at any follow-up point. Surgical procedures performed and vaccination protocols are outlined in online supplementary appendix, Table 2.

5. The Meta-analysis section now reads 'All studies reported on recurrence of disease following treatment, as per the inclusion criteria. The overall recurrence rate was $3.37 \%(n=98)$, with a $1.72 \%$ $(n=23)$ recurrence rate in the vaccinated group and $4.76 \%(n=75)$ in the unvaccinated and placebo group. Meta-analysis demonstrated a reduction in recurrence of CIN2 +in the vaccinated group compared with the unvaccinated group (OR $0.34,95 \% \mathrm{CI} 0.21$ to $0.54, \mathrm{p}=<0.00001$, Figure $3 \mathrm{~A}$ ). The number needed to treat calculated for the five studies was 27.

In sub-group analysis, we analyzed if the time of vaccination influenced cervical intraepithelial neoplasia $2+$ recurrence rates. Three of the five studies ${ }^{13,20,22}$ reported on pre-treatment vaccination. The pre-treatment group included $\mathbf{8 0 6}$ vaccinated patients and $\mathbf{1 0 2 5}$ who received either a placebo or Hepatitis A vaccine. Recurrence of cervical intraepithelial neoplasia 2+was reduced in the vaccinated group compared with placebo ( $0 \mathrm{R} 0.40,95 \% \mathrm{CI} 0.21$ to $0.78, p=0.007$ Figure 1 ). The number needed to treat to prevent one recurrence was 37 .

Two studies ${ }^{19,21}$ reported on vaccination after surgical treatment. The post-treatment group included $\mathbf{5 3 2}$ vaccinated patients and $\mathbf{5 4 9}$ unvaccinated patients. Vaccination after surgical treatment reduced recurrence compared with those who received no vaccine $(\mathrm{OR} 0.28,95 \% \mathrm{Cl} 0.14$ to 0.56 , $\mathbf{p}=\mathbf{0 . 0 0 0 3}$ online supplementary appendix figure $3 \mathrm{C}$ ). The number needed to treat in the posttreatment vaccination group was $\mathbf{3 0}$.

6. The NNT calculations within online supplementary appendix 1 has also been updated.

7. Figure 3 has also been updated to take into account the number change. Please see corrected version below.

Figure 3 Forest plots. (A) Overall CIN recurrence. (B) CIN recurrence-pre-treatment vaccination. CIN, cervical intraepithelial neoplasia.

A

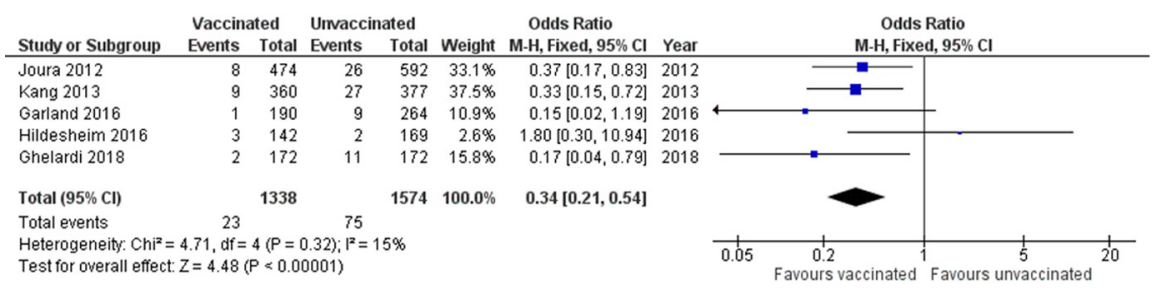

B

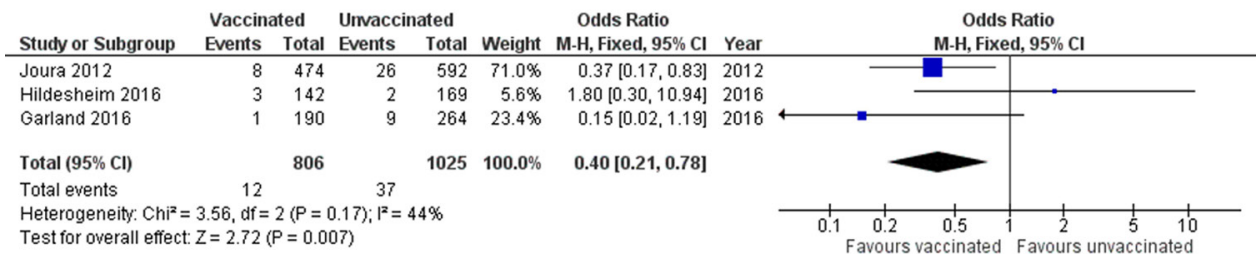

(C) Author(s) (or their employer(s)) 2020. No commercial re-use. See rights and permissions. Published by BMJ. Int J Gynecol Cancer 2020;30:1085-1086. doi:10.1136/ijgc-2020-001197corr1

Check for updates 